\title{
Frequency of Technical Errors in the Biopsy Samples Submitted to an Oral and Maxillofacial Pathology Laboratory
}

\author{
Sadri D', Farhadi $\mathbf{S}^{2 *}$, Mohammadi $\mathbf{M}^{3}$, Seyedpour SM $\mathbf{S}^{4}$ \\ ${ }^{1}$ Associate professor, Oral \& Maxillofacial pathology dept., Dental branch of Tehran, Islamic Azad University, Tehran, Iran \\ ${ }^{2}$ Assistant professor, Oral \& Maxillofacial pathology dept., Dental branch of Tehran, Islamic Azad University, Tehran, Iran \\ ${ }^{3}$ Student of Dentistry, Dental branch of Tehran, Islamic Azad University, Tehran, Iran \\ ${ }^{4}$ Dentist
}

\begin{tabular}{l}
\hline ARTICLE INFO \\
\hline Article Type \\
Original Article \\
Article History \\
Received: Jan 2017 \\
Accepted: Feb 2017 \\
ePublished: Apr 2017 \\
\hline
\end{tabular}

\section{Keywords:}

Technical error,

Biopsy,

Sampling,

Pathology

\section{ABSTRACT}

Background and aim: Following a correct biopsy protocol is crucial for accurate diagnosis of oral and maxillofacial lesions. Pre-analysis technical errors during preparation and submission of biopsies can jeopardize the diagnostic process and the related treatment plan. The aim of the present study was to evaluate pre-analysis technical errors in the biopsy samples submitted to an oral and maxillofacial pathology laboratory.

Materials and methods: In this descriptive study, 166 biopsy samples submitted to the oral and maxillofacial pathology laboratory of the dental branch of Islamic Azad University of Tehran in 2013 were assessed. 13 samples were excluded due to incomplete information. 153 samples were evaluated and compared to the standard criteria with regard to four fields including: biopsy request form, storage solution, container, and quality. The frequency of errors was reported with $95 \%$ confidence interval.

Results: No errors were detected in 19 samples (12.4\%); whereas, 123 samples $(80.4 \%)$ had incomplete biopsy request forms, 7 samples $(4.6 \%)$ had been kept in improper storage media, 2 samples $(1.3 \%)$ had unsuitable containers, and 2 biopsies $(1.3 \%)$ had poor quality.

Conclusion: It seems that failure to submit a complete biopsy request form is the most common technical error, which indicates the need for periodic retraining and updates regarding the biopsy protocols.

Please cite this paper as: Sadri D, Farhadi S, Mohammadi M, Sayahpour SM. Frequency of Technical Errors in the Biopsy Samples Submitted to an Oral and Maxillofacial Pathology Laboratory. J Res Dent Maxillofac Sci. 2017;2(2):2933.

\section{*Corresponding author:}

Sareh Farhadi

Email:dr.sfarhadi@gmail.com 


\section{Introduction:}

Following a correct biopsy protocol is crucial for accurate diagnosis of oral and maxillofacial lesions. Similar to other laboratory procedures, biopsy sampling is susceptible to errors, which can affect the diagnosis. ${ }^{(1)}$ Harvesting a suitable piece of tissue during biopsy procedure is one of the major concerns that affects the final diagnosis and the related treatment plan..$^{(2)}$

Clinically, biopsy is defined as a procedure in which a piece of vital tissue is cut and studied under microscope for diagnostic and therapeutic purposes. ${ }^{(3,4)}$ Histopathological laboratory procedures consist of nine steps, as follows: 1 . Assessment and inquiry, 2. Harvesting the sample, 3. Registering the information, 4. Sample transportation, 5. Sample preparation, 6. Analysis 7. Report, 8. Interpretation, 9. Therapeutic findings. ${ }^{(5,6)}$

The whole mentioned process is usually divided to three analytical stages: 1. Pre-analysis, 2. During analysis, 3. Post-analysis. Pre-analysis errors occur during sample harvesting, and include: smashing, stretching, rotation, and shrinkage of samples (which cause histologic artifacts), biopsy autolysis, damaged samples, and failure to register correct information on the biopsy containers. Errors during analysis occur upon slide preparation, and include bubble formation and inappropriate staining. Post-analysis errors include improper answering or incorrect diagnosis of lesions. . $^{(3,4,7,8)}$

Rotation and shrinkage of the sample cause histologic artifacts in the microscopic view. Biopsy autolysis may occur due to delay in sample fixation, incorrect use of neutral buffered formalin, and unsuitable concentration or inadequate volume of the fixative solution. Samples may also get damaged during removal from a container with a small opening. ${ }^{(9-11)}$

Nonetheless, technical errors in biopsy submission may affect the diagnosis, and jeopardize patients' safety. They may also cause delay in diagnosis which might lead to morbidity and mortality. ${ }^{(12)}$

To date, various biopsy submission errors have been reported in different studies; however, the number of these studies is limited. The aim of the present research was to determine the frequency of errors in the biopsies submitted to the oral and maxillofacial pathology laboratory of the dental branch of Islamic Azad University of Tehran in 2013.

\section{Materials and Methods:}

In this descriptive study, all the samples submitted to the oral and maxillofacial pathology department during 2013 were evaluated with regard to four categories including: biopsy request form, storage solution, container, and quality. The gathered data were compared with the standard criteria. ${ }^{(8)}$ The frequency of errors was reported with $95 \%$ confidence interval.

\section{Results:}

No errors were detected in 19 samples (12.4\%); whereas, 134 samples $(87.6 \%)$ contained errors at least in one of the evaluated categories (CI $95 \%=82.4-92.8)$. (Diagram 1)

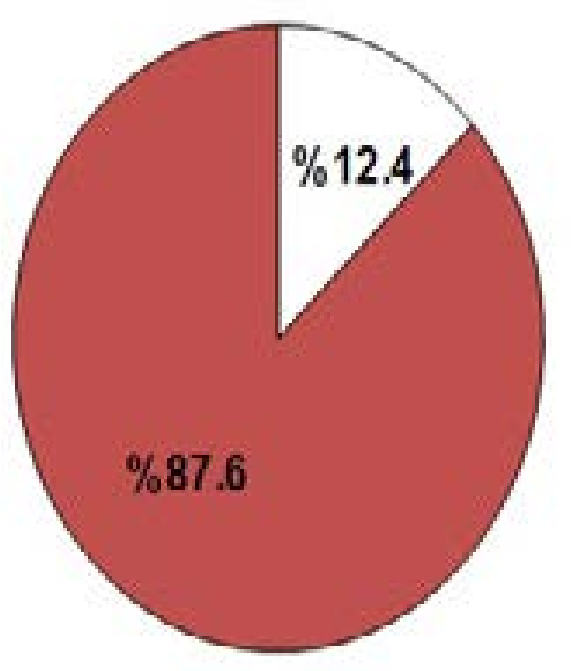

Withoutenor Error percentage 
123 samples $(80.4 \%)$ had incomplete biopsy request forms, 7 samples (4.6\%) had been kept in improper storage media, 2 samples $(1.3 \%)$ had unsuitable containers, and 2 biopsies $(1.3 \%)$ had poor quality. (Table 1)

Table 1- Frequency of errors in the biopsies submitted to the oral and maxillofacial pathology department of the dental branch of Islamic Azad University of Tehran in 2013.

\begin{tabular}{ccc}
\hline $\begin{array}{c}\text { Type of } \\
\text { error }\end{array}$ & $\begin{array}{c}\text { Frequency of } \\
\text { samples with error }\end{array}$ & $\begin{array}{c}\text { Percentage of } \\
\text { samples with error }\end{array}$ \\
\hline $\begin{array}{c}\text { Without error } \\
\text { Biopsy request form }\end{array}$ & 19 & 12.4 \\
\hline $\begin{array}{c}\text { Storage solution } \\
\text { Biopsy } \\
\text { container }\end{array}$ & 7 & 80.4 \\
\hline $\begin{array}{c}\text { Quality of the } \\
\text { sample }\end{array}$ & 2 & 1.3 \\
\hline
\end{tabular}

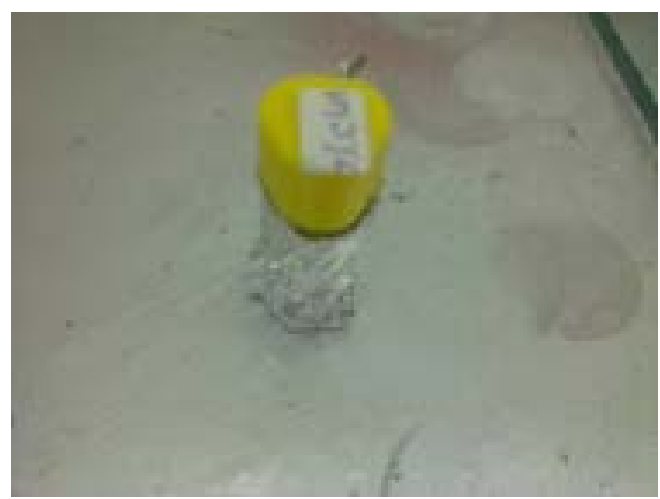

Figure 1- An unsuitable biopsy container

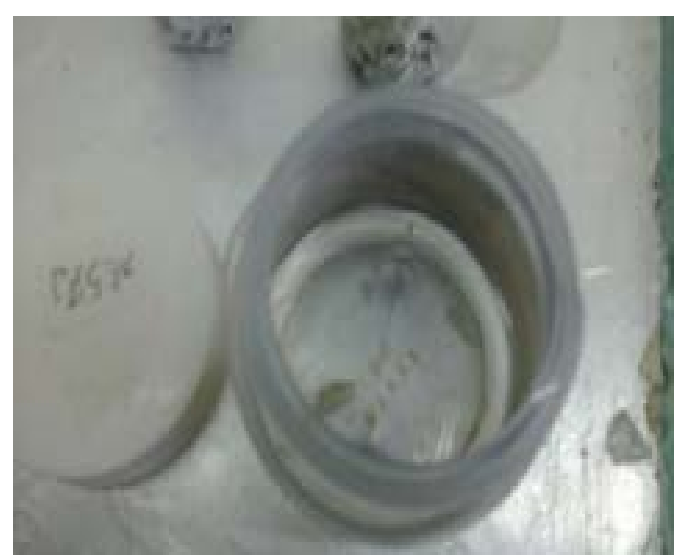

Figure 2- Submission of a small and traumatized sample

\section{Discussion:}

In the present study, $80.4 \%$ of the samples presented with errors related to biopsy request forms, which lacked patient name, age, medical history, sample harvesting area, differential diagnosis, name and especially of the requesting physician, radiographs, and history of previous biopsy). $4.6 \%$ of the errors were related to biopsy storage solution (use of insufficient volume of formalin, or use of non-formalin solutions), $1.3 \%$ of the samples had errors in the sample container (unsuitable size of container, unlabeled containers, or both), and $1.3 \%$ of the samples had poor quality (small sample size, superficial sampling, and traumatized samples). In a study by Zargaran et al, $60.4 \%$ of the errors were related to biopsy request forms, $8 \%$ of the errors were detected in biopsy storage solutions, $19 \%$ in the sample container; while, $12.6 \%$ of the errors were related to the quality of samples. The most common error was an improper biopsy request form, which is similar to the findings of the present study.(1) In the study by Carraro et al, the frequency of this error was equal to $61.9 \%$. $^{(13)}$ In the current study, the most frequent errors were incomplete biopsy request forms, unsuitable storage solution and sample container, and poor biopsy quality, respectively. These results are similar to the findings of the study by Zargaran and colleagues ${ }^{\left({ }^{(1)}\right.} \mathrm{In}$ the study by Wagar et al, the most common error was submission of unlabeled samples, which complicated sample identification. ${ }^{(2)}$ This error was not encountered in our study.

It seems that sending labelled packages containing $10 \%$ formalin to the biopsy centers of the university and private clinics have reduced the frequency of this error in our study.

We found that incomplete biopsy request forms with the frequency of $87.5 \%$ (138 cases), was the most frequent error. Recording the age, sex, alcohol consumption or smoking habits, appearance of the sample, presence or absence of other illnesses, type of biopsy and differential diagnosis are essential for diagnosing pathologic lesions, since diagnosis of some lesions depends on the age, sex, or certain occupations. It should be noted that rendition of differential diagnosis is valu- 
able in the diagnosis of biopsy samples, as it shows the clinician's clinical point of view. ${ }^{(14)}$

Incomplete clinical information and absence of a differential diagnosis may lead to additional paraclinical tests. Absence of radiographs related to intraosseous lesions leads to inability to make a correct histopathological diagnosis. Although dentistry students and residents study the biopsy-related courses during the third year of their education, there is a need for retraining in this field. ${ }^{(14,15)}$

In a research by Plebani et al, pre-analysis error rate was reported to be 50 to $75 \%$. $^{(15)}$ It seems that the $87.6 \%$ error rate in the present study is concerning, and shows the need for retraining and updates regarding the biopsy protocols. According to the performed evaluations, it seems that submission of incomplete biopsy request forms by biopsy performers is the most common pre-analysis error. It is recommended to send standard request forms and pamphlets to different departments of the dental branch of Islamic Azad University of Tehran.

\section{Conclusion:}

It seems that failure to submit a complete biopsy request form is the most common pre-analysis technical error, which indicates the need for periodic retraining and updates regarding the biopsy protocols.

\section{Conflicts of Interest:}

the authors of this manuscript certify that they have no conflicts of interest regarding this research.

\section{Acknowledgement:}

We are thankful to those who helped us in this article including research center of Islamic Azad University, Dental Branch of Tehran.

\section{References:}

1.Zargaran M.a, Baghaei F.b, Moghimbeigi A.c, Shojaeian MS.d. Evaluation of Pre-analytical Biopsy Specimen Errors in the Pathology Laboratory of Hamadan School of Den- tistry. J Dent Shiraz Univ Med Scien 2012; 13(3): 103-9.

2.Wagar EA, Tamashiro L, Yasin B, Hilborne L, Bruckner DA. Patient safety in the clinical laboratory: a longitudinal analysis of specimen identification errors. Arch Pathol Lab Med 2006;130:1662-8.

3.Mota-Ramírez A, Silvestre FJ, Simó JM. Oral biopsy in dental practice. Med Oral Pathol Oral Cir Bucal 2007; 12: 504-10.

4.Seoane J, Varela-Centelles PI, Ramírez JR, Cameselle- Teijeiro J, Romero MA. Artefacts in oral incisional biopsies in general dental practice: a pathology audit. Oral Dis 2004; 10: 113-7.

5.Start RD, Cross SS, Smith JH. Assessment of specimen fixation in a surgical pathology service. J Clin Pathol 1992; 45: 546-7.

6. Poh CF, Ng S, Berean KW, Williams PM, Rosin MP, Zhang L. Biopsy and histopathologic diagnosis of oral premalignant and malignant lesions. $\mathrm{J}$ Can Dent Assoc 2008; 74: 283-8.

7.Meghana SM, Ahmedmujib BR. Surgical artefacts in oral biopsy specimens: Punch biopsy compared to conventional scalpel biopsy. J Oral Maxillofac Pathol 2007;11:11-4.

8.Carraro P, Plebani M. Errors in a stat laboratory: typesand frequencies 10 years later. Clin Chem 2007; 53:1338-42

9.Abbey LM, Sweeney WT. Fixation artifacts in oral biopsy specimens. Va Dent J 1972; 49: 31-4. 10.Sharif MA, Mushtaq S, Mamoon N, Jamal S, Luqman M. Clinician's responsibility in Pre-Analytical Quality Assurance of Histopathology. Pak J of Med Sci 2007; 23(5): 720-3.

11. Kim SH, Choi HS, Chun HJ, Yoo IK, Lee JM, Kim ES, et al. A Novel Fixation Method for Variable-Sized Endoscopic Submucosal Dissection Specimens: An In Vitro Animal Experiment. PLoS One. 2016; 11(1):e0146573.

12.Valenstein PN, Sirota RL. Identification errors in pathology and laboratory medicine. Clin Lab Med 2004; 24: 979-96.

13.Zargaran M. A Review of Biopsy in Dentistry: Principles, Techniques, and Considerations. J Dent Mater Tech 2014; 3(2): 47-54. 
14. Plebani M, Sciacovelli L, Aita A, Chiozza ML. Harmonization of Pre-analytical quality indicators. Biochem Med (Zagreb).2014 Feb 15;24(1):105-13.

15.Allen CM. The oral pathology report: submission of specimens and interpretation of results. Dermat Ther 2002;15:179-84. 